\title{
Best Practice Standards and Methodology for Crane Operator Training-A Global Perspective
}

\author{
Richard Skiba \\ LRES Training Management, Melbourne, Australia \\ Email: richard@skiba.com.au
}

How to cite this paper: Skiba, R. (2020) Best Practice Standards and Methodology for Crane Operator Training-A Global Perspective. Journal of Transportation Technologies, 10, 265-279. https://doi.org/10.4236/jtts.2020.103017

Received: May 28, 2020

Accepted: June 29, 2020

Published: July 2, 2020

Copyright (c) 2020 by author(s) and Scientific Research Publishing Inc. This work is licensed under the Creative Commons Attribution International License (CC BY 4.0).

http://creativecommons.org/licenses/by/4.0/

(c) (i) Open Access

\begin{abstract}
Crane operators control mobile or stationary cranes to lift, move and place objects at locations such as building and construction sites, wharves and shipyards. This activity occurs all over the world and is a high risk task with many noted examples of serious incidents and accidents. There are identifiable key causes that have been noted through analysis of the well documented cases and many of these causes are preventable through effective training programs. Internationally, there are not currently consistent approaches to crane operator training program content or duration. Leading causes of crane accidents are firstly discussed and identified as areas for inclusion in training programs. A number of current training approaches from a range of countries are then considered and these are used to outline the basis of a generic competency standard for crane operation, as it was found that there are not common standards in place. The proposed competency standard can be adapted by training regulators, training providers, government agencies, industry bodies and enterprises as a benchmark for the development of effective training programs.
\end{abstract}

\section{Keywords}

Health and Safety, Vocational Training, Crane Operation, Work Practices, Risk Management, High Risk Work

\section{Introduction}

Crane accidents and incidents are apparent wherever cranes are used with many examples and statistical records available in some cases. Davis [1] notes however, that the volume of crane accidents can only be estimated, and the definition of "accident" is not universal. Davis outlines that some businesses may include only events that result in injury or death, some loss data reports do not include liability 
considerations. And other reports include only some industry segments, while others exclude some categories. Davis identifies that even the definition of a crane is not in agreement, internationally and nationally in some instances. Some definitions exclude non-construction cranes such as industrial gantry, bridge and jib cranes, while others exclude longshore or mining operations.

In some cases, there are well documented incidents that can be utilised as case studies and for future learnings. As an example, In Queensland (Australia), Work Cover Queensland [2] report that between July 2013 to June 2018, there were 244 accepted workers' compensation claims involving injuries where workers have been struck by moving or falling objects or trapped by moving machinery activities involving cranes. Approximately one third (35\%) of these claims were serious (involving five or more workdays absent).

From July 2013 to June 2019, Workplace Health and Safety Queensland (WHSQ) was notified of 112 incidents of people sustaining an injury or at risk of a serious injury as a result of the toppling or other failure relating to an overhead or gantry crane, or failure of a load/lift involving an overhead or gantry crane. WHSQ has issued 69 statutory notices across all industries relating to the risk management of such incidents.

Regarding North American incidents, Lee [3] outlines that according to data provided by the U.S. Bureau of Labor Statistics, on average, 70 construction workers are killed each year in crane-related deaths. For statistical purposes, the term "crane-related" pertains to not only the physical operation of a crane, but also secondary crane accidents, such as those including ground personnel. The U.S. Bureau of Labor Statistics [4] reports that from 2011 to 2015, the Census of Fatal Occupational Injuries (CFOI) reported 220 total crane-related deaths, an average of 44 per year over this 5 -year period.

There are many notable examples of crane incidents internationally. Crane Accidents [5] provides a number of examples including a runaway crane in 2019 in Russia where the crane driver had only left the vehicle for a couple of seconds to readjust a rear-view mirror and failed to apply the handbrake properly. As a result, the crane ran across the road and crashed through the riverside posts/railings before almost dropping into the water. In another example, a tower crane collapsed the morning of January 23, 2019 while it was being dismantled in the city of Yueyang, in the North Eastern corner of Hunan Province, China. At least four people were struck directly by the falling crane tower and jib, two of them died at the scene, while a further two died shortly after they arrived at the hospital.

In the UK, a 70 ton Sennebogen 673E telescopic crawler crane tipped onto its counterweight in October, 2019. Also in the UK, the jib of a Spierings mobile self erecting tower crane broke free and dropped onto the job site where it was working on November 21, 2019. As a final example, one man died and two were injured, one very seriously, after a tower crane dropped a fully loaded 53 cubic feet skip of concrete onto the men, who were working in the pour area below. The 
incident occurred on a site for a new 12 story apartment block in Victoria, Australia. These are just a few examples and other such examples can generally be found wherever cranes are used.

There are a number of common occurrences in incidents involving cranes. The first of these relates to tipping and any tipping incident can be extremely dangerous for both the crane operator and the other workers in the area surrounding a crane [6]. All cranes have weight limits to ensure that the crane will not tip over [7]. To counterbalance the weight, cranes use counterweight and outrigging systems and tipping incidents are commonly related to improper use of outriggers. This can occur in several different ways but is largely related to unsuitable ground conditions, including depressions, voids, excavations, and uneven grading. When the outrigger pad is positioned on unlevel, wet, or otherwise unstable surfaces, there may be an inability to control crane positioning.

Another common occurrence in crane incidents is related to failed rigging which often arises from human error, ranging from improper adherence to procedure to utilizing broken or failing parts. There are also occurrences of boom collapse due to improper weight calculation by the operator. Not adhering to weight limits and incorrect use of load charts can cause boom collapse, dropped loads, and tipping.

There are also a number of cases of electrocutions due to overhead power lines. In Queensland, Australia, there was recently (in 2019) an incident where a mobile crane contacted overhead powerlines. In this case, one worker was electrocuted, another suffered serious injuries, while a third required hospital treatment. Safework NSW [8] advises that since July 2011 to February 2013, there were a total of 55 incidents reported where cranes, machinery and other mobile plant have come into contact with power lines in New South Wales, Australia, alone. Block O'Toole \& Murphy [7] outline that contact with powerlines is a common cause of crane accidents, responsible for as much as 45 percent of all crane accident cases in the United States, according to the Occupational Safety and Health Administration (OSHA). The prevalence of incidents related to use of this high risk plant warrants a consideration of the principal skills required of crane operators and the competence that need to be developed to reduce the occurrence of these incidents. As can be derived from the examples presented, crane incidents are not limited by geography and the ensuing discussion and findings are applicable international context.

\section{Method}

A qualitative approach is utilised to gain a stronger understanding of the underlying principles of crane incidents and accidents and the role of training in their prevention. The discussion and conclusions drawn are based on a literature review together with consideration of the current practices in training and assessing crane operator competence internationally. Noted best practice is outlined within a specific context, where training and assessment is related to crane oper- 
ation, particularly with a view to prevent commonly occurring crane incidents and accidents. The discussion firstly establishes the types of accidents and incidents that occur, with international examples, to derive common causes which then spotlight areas of focus for training programs. These are then framed up as a model competency specification which can be used as a baseline or standard for the development of crane operation training programs in a range of contexts, such as those leading to licencing, enterprise based programs and vocational education and training programs.

\section{Discussion}

\subsection{Leading Causes of Crane Accidents and Incidents}

Gharaie, Lingard \& Cooke [9] identify the main types of crane-related fatalities as follows: failure of boom/cable; crane tip over; electrocution; struck by load-other than failure of boom/cable; falls; crushed during assembly/disassembly; and, struck by cab/counterweight. The Crane Industry Council of Australia [10], referred to the Gharaie, et al. [9], study and surmised that when you look at root causes, risk management and skill/training are paramount. They suggest that there are always going to be physical constraints and planning challenges, but these need to be managed. Management of these risk commences with adequate training.

A model developed by Loughborough University and University of Manchester Institute of Science and Technology (UMIST) considering the causality in construction industry accidents, as discussed in Gharaie, et al. [9], presents that three levels of accident causes can be identified. These are stated as immediate circumstances, shaping factors, and originating influences. According to this model, the immediate circumstances of accidents include the suitability, usability and conditions of tools, equipment and material, the behaviour, motivation and capabilities of workers, and features of the physical site environment such as layout, lighting and weather conditions. Shaping factors are the factors that precede the immediate circumstances, and include factors such as the level of supervision, site constraints, worksite design, poor communication within work team, the state of workers' health, and fatigue.

The Crane Industry Council of Australia [10] identify that the struck by load incident category refers more to loads falling or becoming dislodged and has a very high representation of precast panels, beams and concrete loads. Why these loads struck personnel were due to many reasons ranging from inadequate slinging, unstable stacking/dunnage, booms breaking, cranes tipping, rigging failures and even cranes striking and dislodging stacked material. There were no winch or rope failures. The most prevalent immediate circumstance causes were worker actions and restricted space. The two most commonly identified shaping factors were physical site constraints and design of construction process. Inadequate risk management system was identified as the main originating influence on the accidents. 
According to the U.S. Bureau of Labor Statistics [4], just over half of all fatal crane injuries (between 2011 and 2015) involved the worker being struck by an object or equipment. More than $60 \%$ of these cases (69 of 112) involved the worker being struck by a falling object or equipment and in 60 of these cases, the worker was struck by an object falling from a crane. Transportation incidents and falls to a lower level each made up 14 percent of the remaining fatal injuries involving cranes.

OSHA's analysis of crane accidents, outlined in Graphic Products [11], identified the major causes of crane accidents as boom or crane contact with energized power lines, under the hook lifting device, overturned cranes, dropped loads, boom collapse, crushing by the counter weight and outrigger use, falls and rigging failures.

Health and Safety Executive [12] found that problems arising from workers or the work team, especially worker actions or behaviour and worker capabilities, were judged to have contributed to over two thirds (70\%) of the accidents in their research study related to construction accidents. They suggest that this points to inadequate supervision, education and training. In the context of crane accidents, Lee [3] outlines that most fatal crane accidents can be attributed to the following dangers: electrocution by overhead power lines; blunt force trauma from being struck by crane loads, booms, or jibs; injuries resulting from falls from cranes, crane baskets, or crane loads; and crush injuries resulting from crane collapses. Many of these dangers can be controlled through worker actions or behaviour and worker capabilities.

Shapira and Lyachin [13], cited in Zhao [14], identified 21 major factors affecting safety in tower-crane environments and organised these into major groups: project condition related, environment-related, human-related and safety management related. Among those affecting factors, they identify that operator proficiency is the factor that scored the highest degree of Influence. Zhao also identifies other studies that examined the Hong Kong construction industry and found the factors most affecting the safety in tower crane operations include negligence or misjudgement of participants in tower crane operations, inadequate training, subcontracting practices in tower crane operations, and pressure from deadlines.

\subsection{Legislative Frameworks for Crane Operator Certification}

In many countries, there is a legislative basis in place for certification of crane operators. For example, in the United States of America, OSHA regulations that went into effect in April, 2019, are designed to minimize accidents by strengthening crane operators' knowledge and training. Goodman [15] advise that the regulations, which revised the way that operators are trained, evaluated and certified, put the responsibility for operator readiness on the employer. They apply to a range of construction equipment including mobile cranes, tower cranes, service truck cranes, digger derricks and dedicated pile drivers. The OSHA regulations require crane operators must be certified or licensed and receive ongoing training to operate new equipment. 
The National Commission for the Certification of Crane Operators (NCCCO) outline that Licensing (or "licensure") is the most restrictive of the various forms of what is known as "credentialing" i.e. the process of granting or gaining a "credential". "Certification," on the other hand, they say, is usually a voluntary process instituted by a non-governmental agency in which individuals are recognized for their knowledge and skill. Certification only becomes mandatory if it is adopted by a state or federal agency as the basis of a licensing program (such as the CCO crane operator certification program in West Virginia or New Jersey) or if an employer or project owner requires it as a basis for employment. Currently, 16 states and 7 cities have licensing requirements for crane operators [16].

In Australia, crane operators require a high risk work licence to operate a range of cranes, including bridge and gantry cranes, derrick cranes, non-slewing mobile cranes greater than three tonnes capacity, portal boom cranes, self-erecting tower cranes, slewing mobile cranes, tower cranes and vehicle loading cranes. Before an individual can apply for a national licence to perform high risk work to operate any of these cranes, a registered training organisation (RTO) must assess the applicants training, skills and knowledge using the relevant national 'assessment instrument' under realistic workplace conditions.

To become a Registered Crane Operator in Singapore, individuals must pass the relevant crane operator course conducted by an Accredited Training Provider (ATP) and must have obtained the certificate within 6 months before applying for registration.

Weir [17] outlines initiatives in managing the competence of crane operators in Singapore, where the government's Ministry of Manpower (MOM) is pushing for higher standards to reduce the incidence of accidents and near misses. In 2014 MOM officials visited 80 construction sites in a safety blitz targeted at unsafe lifting practices and crane operations. They found 194 crane-related safety contraventions. Subsequently, there are now three initiatives in Singapore relating to operators: earlier health checks, a tightening of mini crane rules and an operators' database. Since 1 April 2016, crane operators in Singapore have to have biennial health checks from the age of 50 . Singapore requires an individual to be a registered Crane Operator if they want to operate a mobile crane (other than a lorry loader) or tower crane in a workplace. Singapore also has requirements for training in the use of mini cranes. Cranes below five tonnes capacity have previously had certain exemptions. Crane operators who hold a valid mobile or crawler crane licence can continue to operate mini cranes. Those without will have to attend an approved training course.

Throughout Europe, currently each European Member State has its own rules for the professional competence and certification of crane operators [18]. These rules range from compulsory to optional and even to no rules at all. The European Association of Abnormal transport and Mobile Cranes is currently developing the European Crane Operators License (ECOL) which is a European Operator Licensing System aimed at the operators of mobile cranes. The training 
for the ECOL is delivered by training institutes and a precondition for taking part in an ECOL training and examination is that participants are at least 18 years old, and hold of a valid EU class-C driving licence [truck driving licence].

In the United Kingdom, the Construction Plant Competence Scheme (CPCS) provides skills cards for the plant sector of the Construction and allied industries. The CPCS Red Trained Operator Card is issued on successful completion of the CPCS Theory and Practical Technical Tests which must be taken with a CPCS accredited test centre. Individuals must have achieved the relevant CITB Health, Safety and Environment Test within the 2 years before taking the CPCS technical tests. The Blue Competent Operator Card shows employers that individuals are competent to operate a particular type of plant and that they have skills to do the job, the HS\&E training needed to do it safely, and real-world experience with a particular type of plant. Blue Competent Operator cardholders have demonstrated their ability to work unsupervised, and may, in fact be called upon to supervise Red Trained Operator cardholders on the worksite. Red and Blue Cards are available for crane operation and this is not a mandatory scheme.

\subsection{The Need for Operator Training}

The most important reason for any crane safety program is saving lives and a key element to proper crane use is a skilled and knowledgeable operator. Skills and knowledge should be developed through structured and adequate training prior to use of the crane. Based on the identified causes of crane incidents, operator training should at the very least include prevention of contact with powerlines, preventing tipping, ensuring loads are not dropped, preventing counterweight crushing, and correct use of outriggers. In particular, given that, as identified by the Dolman Law Group [19], a large percentage of crane accidents are preventable through the implementation of proper safety procedures and adequate training of crane operators and workers who are in proximity of the crane's operation. They note that, in the U.S., human error is responsible for $90 \%$ of crane accidents and as much as $80 \%$ is due to operation beyond the crane's capacity.

\subsection{Crane Operator Training Programs}

Internationally, there is not a consistent approach to training or training requirements for crane operators. Training may form part of a national system, may be required to meet specific regulator requirements, may have defined competency standards, may have industry endorsement or may be independent of any formal training system.

There are any number of crane operation training programs internationally that are not part of a national or mandatory system. These range from programs delivered by industry groups, employers, professional associations, vocational education and training providers and product suppliers. The Crane Institute of America Mobile Crane Operator training program, as an American example, includes [20]: 
- OSHA \& American Society of Mechanical Engineers (ASME) crane standards

- Causes \& results of crane accidents

- Types of mobile cranes, components \& terminology

- Interpreting load charts correctly

- Pre-operational inspection

- Crane setup and recognizing site hazards

- Safe operating practices \& procedures

- Operator responsibilities

- Pick \& carry operations

- Safety procedures for boom and jib assembly/disassembly

- Safety procedures for working cranes near power lines

- Hand \& voice signals

- Hoisting personnel

- Basic rigging procedures

As another American example, Crane Tech's Mobile Crane Professional Operator Development program [21] is an extensive three-week training providing the knowledge and skills to become a NCCCO certified crane operator. The three-week project is structured as:

- Week 1: Classroom instruction on mobile crane operation including Qualified Rigger Level 1 training and testing to meet OSHA $\$ 1926$ Subpart CC requirements.

- Week 2: Intensive hands-on training where you learn to master load control and prepare for the NCCCO practical exams. Also includes more technical training for load charts, range diagrams, crane set-up, lift planning, hydraulic systems, wire rope inspection, regulations, and pre-operational inspection.

- Week 3: NCCCO Certification written test preparation and written/practical testing.

BCA Academy [22] provides an example of a program designed to meet regulator certification. They offer an 86-hour course that leads to a Certificate of Successful Completion required by MOM for registration to be a tower crane operator for tower crane operation. This training course consists of 2 modules [22]:

Module 1 (Theory)

- Principal components and configuration of tower crane

- Safety devices and indicators

- Introduction to WSHA and subsidiary legislations

- Duties and responsibilities of crane operator

- Interpret load chart

- Risk Assessment and Permit to Work for lifting operation Module 2 (Practical)

- Daily \& weekly inspection

- Initial tower crane operations

- Safety in lifting operations

- Hand signal and telecommunication

- Practical lifting operations 
In UK, an example of a red card course program for mobile cranes is offered by Training Plus [23]. The program covers [23]:

- Legislation-LOLER, PUWER, HASAWA, codes of practice-BS7121

- Roles and responsibilities of personnel involved with lifting operations

- Crane appreciation-crane types, capabilities and limitations

- Duty charts

- Crane Terminology

- Documentation and certification for lifting equipment and lifting accessories

- Crane stability/ground conditions

- Rated Capacity Indicator (RCI) and Safe Working Loads (SWL)

- Lifting accessories, types of accessories and use

- Sling angles

- Communications (Radio, verbal and hand signals, etc.)

- Rigging and de-rigging of cranes according to written instructions

- Configuring cranes according to work specifications

- Hoisting, slewing and derricking following the instruction of the slinger/signaller

- Controlling load movement

- Routine maintenance

- Use of crane on free wheels duties

- Use of crane on pick and carry duties

Crane operation training programs vary in their duration, coverage and certification and as such there is not an applicable or available benchmark for training in this field.

\subsection{Competency Standards}

In an international arena, some countries have highly evolved, detailed and developed competency specifications for crane operation. The Australian units of competency, as part of a national framework, is an example as such. For instance, for an individual to operate a slewing mobile crane with a Maximum Rated Capacity (MRC) up to 60 tonnes, they would need to complete the unit of competency "TLILIC0013-Licence to operate a slewing mobile crane (up to 60 tonnes)" with a Registered Training Organisation approved to undertake training and assessment in the unit. The individual would then be required to undertake licence testing utilising a National Assessment Instrument. New Zealand has also developed unit standards, for example "Configure and position a mobile crane, and lift and place regular and irregular loads". Many of the world's nations do not, however, have national competency standards, or they may not cover crane operation where they do.

Given the variation in the way training in crane operation is applied internationally, a model competency standard is outlined in Table 1, based on examples of current training programs throughout the world and to account for the leading causes crane accidents and incidents. The competency specification, titled "perform crane operations", has been produced as a generic competency specification 
Table 1. Model unit of competence specification for a unit designed to specify competence requirements for crane operators.

\section{Perform crane operations Application}

This unit describes the skills and knowledge required to conduct crane operations, including lifting loads, and positioning and travelling where applicable.

\section{Unit Sector}

Plant Operations

\section{Elements and Performance Criteria}

ELEMENT PERFORMANCE CRITERIA

Elements describe the essential outcomes.

1. Prepare for crane operations

2. Commence crane operations

3. Operate crane within operating capacities of equipment to complete work activity

4. Travel the crane (where relevant to type)

5. Complete crane operations
Performance criteria describe the performance needed to demonstrate achievement of the element.

1.1 Carry out equipment pre-start and start-up checks in line with workplace procedures

1.2 Identify faults or defects and rectify or report within scope of own responsibility and according to workplace procedures

1.3 Inspect and confirm lifting gear is attached according to work requirements, equipment specifications, and workplace procedures

1.4 Confirm the work area is clear and safe prior to commencing work activity

1.5 Confirm ground suitability of work area operating surface for operational use of the crane

1.6 Determine appropriate paths for operating the crane and moving and placing load/s in work area

1.7 Identify hazards and apply risk elimination/control measures

2.1 Position, stabilise and level crane prior to commencement of lift operations

2.2 Correctly interpret relevant load charts

2.3 Confirm weight of load as being within the lifting capacity and operating radius of the crane

2.4 Configure crane for specified lift

2.5 Prepare loads for lift in accordance with crane limitations and rigging requirements, and according to workplace procedures

2.6 Access crane in accordance with manufacturer specifications and safety regulations

2.7 Crane controls and functions, including manoeuvrability, emergency functions, gear and accessories are checked for serviceability and any faults are rectified or reported

3.1 Perform a test list

3.2 Use crane controls and functions to lift and position loads using techniques suited to equipment capabilities, site and work conditions, and according to workplace procedures

3.3 Monitor and manage equipment performance using indicators and alarms

3.4 Monitor hazards and risks during operations, and ensure safety of self, other personnel, plant and equipment

4.1 Plan a firm and level route for the crane travel according to workplace procedures

4.2 Monitor and manage hazards along the route

4.3 Travel the crane in accordance with relevant Standards, manufacturer's guidelines, engineering specifications and organisational policies and procedures and work requirements

5.1 Shut down crane using the correct sequence of procedures in accordance with manufacturer recommendations and specifications and site safety procedures

5.2 Park up, secure and carry out post operational inspection of equipment in line with workplace procedures 


\section{Continued}

6. Conduct housekeeping activities

6.1 Clear work area and dispose or recycle materials according to relevant procedures

6.2 Manage and/or report hazards to maintain a safe working environment

6.3 Complete and file required record keeping, and distribute as required

\section{Assessment requirements}

\section{Performance Evidence}

The candidate must show evidence of the ability to complete tasks outlined in elements and performance criteria of this unit, including:

- locating and applying required documentation, policies and procedures

- selecting and wearing personal protective equipment required for work activities

- monitoring and managing equipment performance using indicators and alarms

- identifying common equipment faults

- selecting and using required tools and equipment

- inspecting and preparing work area

- using a range of communication techniques and equipment essential to the safe completion of work

- completing out pre-start, start-up checks prior to commencing operations, and shut-down procedures on completion of operations

- positioning, stabilising and levelling crane

- lifting and positioning loads

- travelling cranes where relevant to the crane type

- parking and securing equipment

- cleaning-up of work area

- operating the crane to move a variety of loads including:

- loads of greater than $50 \%$ of the Rated Capacity (RC) of the crane with a boom length of extended to at least $50 \%$ of the maximum radius

- $\quad$ asymmetric/irregular loads

- loads and positions requiring use of a range of:

- attachments

- boom up and boom down

- luff movements

- outriggers

- slew left and right

- telescope in and out

- trolley in and trolley out

- winch up and down in combination

\section{Knowledge Evidence}

The candidate must be able to demonstrate essential knowledge to effectively complete the task outlined in the elements and performance criteria of this unit. This includes knowledge of:

- relevant recognition, permit, licence or permission to operate within any region, locality, state or territory issued by the government regulatory authority of that jurisdiction

- acting responsibly and understanding consequences of own actions related to crane operations

- policies and procedures relating to own role and responsibility

- relevant legislation, regulations, codes of practice, policy and national standards likely to impact on the crane operations

- crane terminology

- hoisting terminology, functions and systems

- causes of crane incidents and accidents and their prevention 


\section{Continued}

- recognising site hazards

- key features associated with equipment performance including technical capabilities and limitations and equipment specifications

- different elements of load charts: specifications, range diagram, work area diagram, boom/jib erection charts, rated capacity charts

- crane stability/ground conditions

- calculation of ground bearing pressure and required outrigger padding

- calculation of net capacity, including factors such as rigging weight, limiting factors (e.g. line pull restriction, winch capacity), intermediate values on capacity charts (boom length, radius, boom angle)

- safety procedures for working cranes near power lines

- safety procedures for boom and jib assembly/disassembly

- Rated Capacity Indicator (RCI) and Safe Working Loads (SWL)

- lifting accessories, types of accessories and use

- types and function of wire and chains

- calculating the SWL/WWL for wire rope and rigging

- hoisting, slewing and derricking following the instruction of the slinger/signaller/dogger

- correctly setting up of counterweight(s)

- correctly setting up jib/fly jib/luffing fly (where relevant/fitted)

- correct use of outriggers (where relevant/fitted)

- use and function of operator aids, including load moment indicator (LMI), anti-two block device/two-block damage prevention systems, boom angle indicator, boom length indicator

- alternative operating procedures when operator aids malfunction

- environmental conditions that can impact on crane operations

- safety requirements for working near trenches/excavations

- crane operator's authority to stop operations

\section{Assessment Conditions}

Gather evidence to demonstrate consistent performance in conditions that are safe and replicate the workplace. Conditions must be typical of those experienced in a typical crane operation environment and include access to:

- relevant and appropriate materials, tools, equipment and personal protective equipment currently used in industry

- appropriate loads as outlined in the performance evidence requirements

- appropriate personnel to sling and direct loads including slinger/dogger/rigger

- applicable documentation including:

- approved codes of practice and relevant guidance material

- relevant technical standards

- manufacturer guidelines (instructions, requirements or checklists), relevant industry standards and operating procedures (where applicable), load charts relevant to the specific crane(s)

Assessors must satisfy the requirements for assessors in applicable legislation, frameworks and/or standards.

for crane operation rather than focusing on particular classes of crane. The specification can be adapted by local, state or national regulators for inclusion in their training system, or likewise can be used by training organisations as a basis for their training programs. Where training programs are delivered by enterprise or industry, the competency standard can also be utilised as a basis for their training programs.

The competency standard as outlined in Table 1, can be adapted and extended to be utilised as standard for a variety of crane types or classes. Given that the 
model presents a baseline for competency development, it provides a model for best practice for development of training and assessment systems, providing users with a common framework. Likewise, it can be contextualised to meet specific industry or organisational requirements.

The competency standard also addresses and allows for training to emphasise load chart interpretation. The National Commission for the Certification of Crane Operators [16] outline that knowledgeable crane experts all agree that there is no more abused, misunderstood, or just plain ignored aspect of mobile crane operations than the crane's load chart, a fact NCCCO can confirm based on its experience of administering hundreds of thousands of written tests. They outline that without a thorough understanding of a mobile crane's load chart, an operator cannot have an accurate picture of either its capabilities or its limitations.

\subsection{Training Program Duration}

Examining the range of training programs and approaches applied internationally, there are no general common approaches to crane operator training duration. The duration of the training programs are generally not mandated and can vary locally, regionally and nationally.

The ECOL training consists of a theoretical and a practical part, each lasting a minimum of 120 hours for novice operators [18]. An experienced operator, however, has the possibility to follow the ECOL programme with a reduced duration where crane operators with four to eight years of operating experience have to do a three-week training program, consisting of 40 hours practice and 80 hours theory, and take the examination. Crane operators with eight or more years of operating experience have to do a one-week training program, consisting of 16 hours of practice and 16 hours of theory, after which they will take the examination.

In the Australian system, the average duration to complete Licence to operate a slewing mobile crane (up to 60 tonnes) is 36 Hours and CPCCLTC4001A Licence to operate a tower crane is conducted on average over 6 days [24]. The duration then, in Australia, varies with the class of licence and is determined by the training provider delivering the training.

The North American NCCCO training usually lasts for 4 to 8 weeks, can be of several months' duration depending on the type of crane certification being sought.

Crane training programs must give participants the opportunity to fully absorb the required knowledge and develop skills over time in the different contexts they would experience in the workplace. There must also be sufficient time for the participant to practice and consolidate knowledge and skills. Participants must be given the opportunity to practise or implement their new ideas.

Given the range of variation noted in current programs, the norms would indicate a training duration of 80 to 120 hours for a novice crane operator would be suitable. The competency standard, as provided in Table 1, would reasonably require at least 80 hours to deliver. 


\section{Conclusions}

In all parts of the world where cranes are utilised, there is evidence of serious incidents and accidents occurring. Crane collapse or falling loads can cause serious injuries, fatalities as well as damage to property on and off site. Unsafe use of crane equipment presents significant risk potential for people and property and many of the cases where accidents occur, they could have been prevented through adequate training prior to operation.

There are currently no international standards or benchmarks for training in crane operations and there is a great degree of variation in the way these programs are delivered. Nevertheless, crane operator training should address the aspects of crane operations that are potentially the highest risk areas, in order to minimise or prevent accidents and incidents. The training should fully cover all aspects of crane operation including prepare for crane operations, commencing crane operations, operating crane within operating capacities of equipment to complete work activity, travelling the crane and completing crane operations. This includes causes of crane incidents and accidents and their prevention. Effective training in crane operations in the key to crane accident and incident prevention.

\section{Conflicts of Interest}

The author declares no conflicts of interest regarding the publication of this paper.

\section{References}

[1] Davis, B. (2009) Boom! What Was That Noise? Common Causes of Crane Accidents and How to Prevent Them. https://www.onepetro.org/conference-paper/ASSE-09-525

[2] WorkCover Queensland (2020) Worker Injured by Overhead Travelling Crane. https://www.worksafe.qld.gov.au/injury-prevention-safety/alerts/incident-alerts/201 9/worker-injured-by-overhead-travelling-crane

[3] Lee, S. (2020) Causes and Prevention of Harmful Crane Accidents. https://www.attorneystevelee.com/our-library/causes-and-prevention-of-harmful-cr ane-accidents/

[4] U.S. Bureau of Labor Statistics (2017) Fatal Occupational Injuries Involving Cranes. https://www.bls.gov/iif/oshwc/cfoi/cranes_fact_sheet.htm

[5] Crane Accidents (2020) Crane Accident News. https://www.craneaccidents.com/

[6] Prolift (2020) Common Causes of Crane Accidents and How to Prevent Them. https://proliftcrane.com/common-causes-crane-accidents-prevent/

[7] Block O’Toole \& Murphy (2020) Common Causes of Crane Accidents. https://www.blockotoole.com/blog/2013/02/5-common-causes-of-crane-accidents.s $\underline{\mathrm{html}}$

[8] Safework NSW (2013) Mobile Plant Operating near Overhead Power Lines Safety Alert.

https://www.safework.nsw.gov.au/safety-alerts/safety-alerts/mobile-plant-operating -near-overhead-power-lines 
[9] Gharaie, E., Lingard, H. and Cooke, T. (2015) Causes of Fatal Accidents Involving Cranes in the Australian Construction Industry. https://epress.lib.uts.edu.au/journals/index.php/AJCEB/article/view/4244/4797 https://doi.org/10.5130/AJCEB.v15i2.4244

[10] Crane Industry Council of Australia (2020) Crane Accident Analysis. https://www.cica.com.au/bulletin-245

[11] Graphic Products (2020) Crane Accidents. https://www.graphicproducts.com/articles/crane-accidents/

[12] Health and Safety Executive. (2003) Causal Factors in Construction Accidents. Research Report 156. HMSO and Loughborough University, London.

[13] Shapira, A. and Lyachin, B. (2009) Identification and Analysis of Factors Affecting Safety on Construction Sites with Tower Cranes. Journal of Construction Engineering and Management, 135, 24-33. https://doi.org/10.1061/(ASCE)0733-9364(2009)135:1(24)

[14] Zhao, Q. (2011) Cause Analysis of U.S. Crane-Related Accidents. Masters' Thesis, University of Florida, Gainesville. https://ufdcimages.uflib.ufl.edu/UF/E0/04/29/72/00001/zhao_q.pdf

[15] Goodman, J. (2019) Recent Deadly Accidents, New Regulations Put Crane Safety in the Spotlight.

https://www.constructiondive.com/news/recent-deadly-accidents-new-regulationsput-crane-safety-in-the-spotlight/557704/

[16] National Commission for the Certification of Crane Operators (2020) State \& City Licensing Requirements.

https://www.nccco.org/nccco/resources/industry-resources/state-licensing

[17] Weir, K. (2016) Operator Training and Certification. https://www.khl.com/features/operator-training-and-certification/116825.article

[18] European Association of Abnormal Transport and Mobile Cranes (2020) European Crane Operators Licence. https://ecol-esta.eu/

[19] Dolman Law Group (2020) What Are the Causes of Crane Accidents? https://newportricheyinjury.wordpress.com/2015/12/23/what-are-the-causes-of-cra ne-accidents/

[20] Crane Institute of America (2020) Mobile Crane Operator. https://craneinstitute.com/operator-training/mobile-crane-operator/

[21] Crane Tech (2020) Mobile Crane Professional Operator. https://www.cranetech.com/mobile-crane-training/mobile-crane-professional-oper ator/

[22] BCA Academy (2020) Tower Crane (Saddle JIB) Operation. https://www.bcaa.edu.sg/what-we-offer/courses/certification-courses-for-tradesmen ?CourseId=079525c2-3230-6ef1-b0a0-ff0000a28c6c

[23] Training Plus (2020) CPCS Mobile Crane. https://trainingplus.com/find-a-course/cpcs-mobile-crane/

[24] Australian Government (2020) Myskills. https://www.myskills.gov.au/ 